\title{
Los municipios de sexta categoría de Colombia (2000-2016): entre la autonomía y la dependencia*
}

\author{
Siervo Tulio Delgado Ruiz** \\ Johanna Inés Cárdenas Pinzón *** \\ Héctor Javier Fuentes López ${ }^{* * * *}$
}

Fecha de recepción: 21 de octubre de 2019

Fecha de aprobación: 10 de enero de 2020

Resumen: La implementación y evolución del proceso de descentralización en Colombia en materia fiscal y administrativa ha ido trasladando competencias, funciones y responsabilidades hacia los gobiernos locales, dotándolos de recursos para asumir los nuevos compromisos a través de la transferencia de recursos del nivel central al territorial, en un escenario donde los tributos de mayor recaudo pertenecen a la nación, en tanto que los municipios se deben financiar con gravámenes limitados en términos de cantidad y eficiencia, lo que los hace depender, en mayor grado, de los dineros transferidos desde el gobierno central. Este es el caso del $87.9 \%$ de los municipios del país, clasificados como de sexta categoría de acuerdo con los parámetros establecidos en la Ley 617 del 2000, cuya baja capacidad de autofinanciamiento y alto nivel de dependencia fiscal dio origen al presente artículo, en el cual se aborda esta problemática con un análisis de causalidad, basado en el uso de estimaciones econométricas.

Palabras clave: autonomía territorial, dependencia fiscal, descentralización, esfuerzo fiscal, transferencias.

Clasificación JEL: H70, H72, H75, H76, H77. Cómo citar este artículo/ To reference this article / Comment citer cet article / Para citar este artigo:

Delgado Ruiz, S., Cárdenas Pinzón, J., \& Fuentes López, H. (2020). Los municipios de sexta categoría de Colombia (2000-2016): entre la autonomía y la dependencia. Apuntes del Cenes, 39(69). Págs 137 - 167 https://doi. org/10.19053/01203053.v39.n69.2020.10172

* Artículo resultado de la actividad del grupo de investigación Modelos de Desarrollo en América Latina- MODEAL de la Escuela de Economía de la Universidad Pedagógica y Tecnológica de Colombia, con el proyecto titulado "Análisis comparativo de la dependencia fiscal de los municipios de sexta categoría en los departamentos de Boyacá y Antioquia, 2005-2016".

** Economista, especialista en Gestión de Proyectos y magíster en Economía. Docente de la Escuela de Economía de la Universidad Pedagógica y Tecnológica de Colombia. siervo.delgado@uptc.edu.co (2) https://orcid. org/0000-0001-8120-0909

*** Economista, Magíster en Economía. Docente de la Escuela de Economía de la Universidad Pedagógica y Tecnológica de Colombia. johanna.cardenas@uptc.edu.co @ https://orcid.org/0000-0002-4471-0931

**** Economista, Magíster en Ciencias Económicas. Docente titular Universidad Distrital Francisco José de Caldas. Colombia. hjfuentes|@udistrital.edu.co (2) https://orcid.org/0000-0001-6899-4564 


\title{
Municipalities of Sixth Category of Colombia (2000-2016): Between Autonomy and Dependence
}

\begin{abstract}
The implementation and evolution of the process of decentralization in Colombia in tax and administrative matters has been transferring competencies, functions and responsibilities to local governments, providing them with resources to assume new commitments through the transfer of funds from the central to the regional level. It has occurred in a scenario where the highest taxes belong to the nation, while municipalities must be financed with limited levies in terms of quantity and efficiency, which makes them depend, to a higher degree, on the money transferred from the central government. It is the case of $87.9 \%$ of the municipalities of Colombia which are classified as category six municipalities, according to the parameters established in Law 617/2000, and means that they have a low capacity for a self-financing and high level of tax reliance. These factors gave rise to the present article, in which this problem is approached with a causality analysis, based on the use of econometric estimations.
\end{abstract}

Keywords: territorial autonomy, tax reliance, decentralization, tax effort, transferences. 


\section{INTRODUCCIÓN}

Desde finales de la década del ochenta y luego, con la promulgación de la Constitución de 1991, Colombia puso en marcha el proceso de descentralización desde el Estado central al territorial, al trasladar a este último responsabilidades, competencias y recursos, manteniendo en el nivel central los tributos más eficientes y de mayor recaudo (renta, IVA, patrimonio, 4x1000, etc.) y dejando para los territorios aquellos provenientes de la propiedad del suelo y de las actividades económicas (predial, industria y comercio, etc.), que tienen menor recaudo y mayor inflexibilidad, por lo cual era necesario complementarlos con transferencias que permitieran la participación de los gobiernos territoriales en las rentas nacionales, de modo que "se descentralizaron los gastos mientras el gobierno central nacional se quedó con los ingresos" (Delgado \& Acero, 2015, p. 218). Así, ante este nuevo panorama, los entes territoriales conservaron pocas opciones de generación de nuevos tributos, quedando su financiación a expensas, principalmente de los recursos transferidos por el gobierno central.
Para el caso de los municipios, especialmente los más pequeños presupuestalmente hablando, las fuentes de las cuales derivaban los recursos para atender las responsabilidades asumidas por el proceso descentralizador, comprendían los recursos propios, provenientes de una estructura predial soportada por un catastro desactualizado, unas actividades comerciales, industriales y de servicios incipientes o pequeñas en sus territorios y el consumo de combustibles, los cuales oscilan alrededor del $10 \%$ de los ingresos municipales totales, quedando el resto del financiamiento a cargo de los recursos de deuda y los provenientes de las transferencias del nivel nacional o departamental (SGP, regalías, fondos especiales, etc.), lo que los dejó con un alto nivel de dependencia fiscal, limitando sus posibilidades de gasto y de atención a unas demandas sociales crecientes.

Esta problemática originó la elaboración del presente artículo, en el cual se analiza la dependencia fiscal que afrontan los municipios de sexta categoría de Colombia, que constituyen un $87.9 \%$ del total nacional, clasificados de acuerdo con los lineamientos establecidos por 
la Ley 617 de 2000, con el fin de determinar los factores que originan dicha condición. El estudio abarca el periodo 2000-2016.

Al comienzo hay una revisión teórico-conceptual de la orientación que ha tenido la política fiscal, la descentralización y el manejo de las finanzas públicas en Colombia a partir de 1990. Luego se presentan los cálculos de algunos indicadores de gestión financiera de los municipios de sexta categoría de Colombia, para establecer su evolución presupuestal durante el periodo de estudio. En tercera instancia se muestran los resultados de una estimación econométrica, para establecer la relación de causalidad de la dependencia fiscal en los municipios de sexta categoría, a través de la metodología de datos de panel. Y en último término se exponen las conclusiones.

\section{REVISIÓN TEÓRICO-CONCEP- TUAL DEL ACTUAL ENFOQUE DE POLÍTICA FISCAL Y FINAN- ZAS PÚBLICAS APLICADO EN COLOMBIA}

La política fiscal abarca las distintas políticas sobre ingresos y gastos que definen el monto de recursos con los que cuentan las economías, con el objetivo de invertir en el desarrollo de las diversas actividades que realiza el Estado. Es decir, dicha política es uno de los instrumentos que contribuyen a alcanzar objetivos como la redistribución de la riqueza, la corrección de los fallos del mercado, la disminución de la desigualdad, entre otros (Center for Economic and Social Rights [CESR], 2017); e influye "de manera decisiva en la determinación de la realidad económica ya que afecta directamente a la utilización de los recursos agregados y el nivel de demanda agregada de una economía" (Fondo Monetario Internacional -FMI-, 2002, p. 88).

La actual estructura de las finanzas públicas en Colombia surge de los programas de ajuste y de las reformas estructurales adoptadas en la mayor parte de América Latina después de la crisis de la deuda (1982), cuyos principios ideológicos obedecen a la reducción del intervencionismo estatal y a la defensa de la preeminencia del mercado, posturas que han sido influenciadas por organismos como el Fondo Monetario Internacional (FMI), el Banco Mundial (BM) y el Banco Interamericano de Desarrollo (BID) (Giraldo, 2009).

Dentro de los programas de ajuste propuestos en el denominado Consenso de Washington, se encuentra el ajuste a las políticas públicas, y según el FMI (2002), las principales reformas fiscales realizadas en Colombia a principios de los años noventa fueron las privatizaciones, las reformas tributarias, la reestructuración y modernización de la administración pública y la descentralización fiscal .

1 Autores como Bardhan (2002) y Montecinos (2005), afirman que el federalismo fiscal es el sustento teórico de la descentralización fiscal en los países en vía de desarrollo. 


\section{Descentralización fiscal en Colombia}

La descentralización es considerada una de las piezas fundamentales de las reformas económicas e institucionales del Estado en América Latina, las cuales están basadas en la primacía del mercado; al abordar el tema de la descentralización, aproximadamente desde los años ochenta, se hace referencia a la de tipo político y fiscal que significa la transferencia de recursos y competencias del gobierno central a las entidades territoriales (Giraldo, 2009).

Al respecto, Finot (2006), considera:

En una perspectiva histórica, la descentralización política hace parte, ciertamente, de los procesos de democratización iniciados en la década de los 80. Pero además se orientó en función de un objetivo prioritario para la gobernabilidad democrática: amortizar en la brevedad posible lo que la OIT había denominado la 'deuda social'. (p. 1)

En Colombia, la Constitución de 1991 introdujo una serie de reformas fiscales enfocadas en descentralizar el gasto y lograr mejoras en la cobertura de bienes públicos, que modificaron tanto las responsabilidades de gasto de los distintos niveles de gobierno como el sistema de transferencias del nivel central al territorial (Delgado \& Acero, 2015). Para Restrepo (2015), la nueva Carta Política de 1991 intentó organizar un sistema en el cual las entidades territoriales obtuvieran un mayor grado de autonomía y gozaran de unos recursos vía transferencias del presupuesto nacional, esto acompañado también de la transferencia de funciones.

Con la reforma constitucional de 1986 ya se había planteado el sistema de transferencias del gobierno central a los territoriales, pero fue con la Constitución de 1991 y la Ley 60 de 1993 que se aceleró el proceso descentralizador, de tal forma que se establecieron cuatro mecanismos para la distribución de los ingresos: el situado fiscal, la participación municipal, los fondos de cofinanciación y el Fondo Nacional de Regalías (FMI, 2002).

Aghón (1993), planteó algunas de las alternativas para transferir funciones en materia de ingresos y gastos de los niveles de gobierno centrales a los territoriales:

a. Promoción de procesos de descentralización en agregados fiscales (gastos e ingresos estatales), que consistía en que los niveles nacionales y locales decidieran la cantidad de gasto público y los ingresos por recaudar en libre competencia respecto a las demás jurisdicciones y el gobierno central.

b. Determinación de límites estrictos entre los niveles de gobierno, pero permitiendo que los niveles territoriales actuaran discrecionalmente, siempre y cuando se mantuvieran 
dentro de dichos límites, esto con el objetivo de prevenir efectos indeseados.

c. Mayor centralidad del gasto público y del orden tributario, por medio de mayores restricciones a las facultades de los entes descentralizados en materia de ingresos y gastos.

d. Otorgamiento de atribuciones al gobierno central para decidir respecto a la cantidad y calidad de los servicios prestados en niveles inferiores. En algunos casos la competencia fiscal de las entidades territoriales se hace casi inexistente.

En Colombia, desde mediados de los ochenta (Valencia Cárdenas et al., 2016), la financiación del proceso descentralizador se ha venido desarrollando por medio de las transferencias territoriales. Se puede argumentar que de las cuatro alternativas para transferir las funciones presentadas por Aghón (1993), la última corresponde al modelo aplicado en Colombia, ya que según la Ley 715 de $2001^{2}$, las transferencias deben ser utilizadas con designación específica.

\section{Ventajas y desventajas de la descentralización}

Los argumentos presentados en la literatura a favor y en contra de la descentralización han sido variados, estos pueden denominarse externalidades positivas y negativas de los procesos descentralizadores (Bonet, Pérez, \& Montero, 2018), y dentro de las posibles ventajas se encuentran:

En primer lugar, y como principal justificación en defensa de la descentralización, esta permite que los gobiernos centrales se acerquen a las distintas jurisdicciones para, de esta forma, conocer mejor las necesidades de los agentes y lograr una eficiente focalización de las inversiones en bienes y servicios (Oates, 1999).

Del mismo modo, según el Banco Mundial (2001), la descentralización, además de aumentar la autonomía local, favorece la gestión del gobierno y la prestación de servicios públicos, ya que permite mejoras en la eficiencia tanto en la asignación de recursos como en la producción, facilita la reducción de la burocracia y mejora el conocimiento de los costos locales.

Otra de las externalidades positivas que presenta la adopción de esquemas fiscales descentralizados es la relación entre esta y el crecimiento económico a largo plazo. Para Colombia, Lozano y Julio (2016), hallaron relación positiva entre estas dos variables durante las dos últimas décadas.

Al respecto, la Comisión Económica para América Latina considera:

2 La cual reglamenta el Sistema General de Participaciones (SGP). 
[...] por efecto de los procesos de descentralización, la transferencia de competencias a las regiones facilita que tome cuerpo la dimensión político-administrativa de los procesos de desarrollo local endógeno. No se trata solo de que la política de desarrollo territorial derivada de la descentralización sea efectivamente una política de desarrollo, sino, sobre todo, de que el autogobierno de las comunidades locales y regionales se refuerce y los valores culturales y sociales de contenido local se potencien y se desenvuelvan. (CEPAL, 2001, p. 35)

Por otro lado, se exponen algunos de los argumentos que relacionan los procesos descentralizadores como efectos no deseados o externalidades negativas. Aghón (1993), explica que las dificultades pueden presentarse en las funciones de asignación, distribución y estabilización (esta última desde el punto de vista macroeconómico):

a. Asignación: las acciones de política fiscal pueden afectar a algunos agentes que se encuentran fuera de las fronteras de una determinada jurisdicción, ya sea en la prestación de servicios públicos o en la asignación del gasto público, por tanto, a la hora de evaluar las consecuencias sobre el bienestar no se puede decir que se genere una eficiente asignación de los recursos. Además, hay que tener en cuenta que la corrupción generada por el clientelismo es otro de los problemas que surge en la asignación de los recursos. b. Distribución: si los programas de redistribución son diferenciados o no, reflejan soluciones a las principales problemáticas de la población en las distintas regiones y podrían desencadenar problemas migratorios, es por esto que se sugiere que desde los gobiernos centrales se controle la forma en la que las entidades territoriales manejan los niveles de gasto.

c. Efectos macroeconómicos: el aumento de las transferencias puede ampliar las posibilidades de incurrir en un déficit fiscal, pues afecta la capacidad de ahorro de las economías; además, este tiene evidentes consecuencias sobre la estabilización del ciclo económico.

Adicional a estas dificultades, se puede ocasionar un problema, conocido en la literatura económica como la pereza fiscal, el cual hace referencia al efecto que puede tener sobre la recaudación de ingresos propios el aumento de las transferencias por parte del gobierno central.

Algunos estudios, como los de Ramírez y Bedoya (2014), Martínez (2017) y Ramírez y Bedoya et al., (2016), han demostrado que sí existe evidencia de la presencia de dicha externalidad en el país, principalmente en la recaudación del impuesto predial, sobre todo en los municipios que participan en mayor proporción de las regalías; a pesar de que los periodos analizados en estos trabajos fueron previos a la creación del 
Sistema General de Regalías, un estudio más reciente de Bonet, Pérez y Ricciulli (2017) explica que

Los resultados no permiten concluir que las transferencias generen una pereza fiscal en Colombia, ya que las mayores transferencias no implicaron una menor recolección de recursos propios en los $\mathrm{GSN}^{3}$. Las dos fuentes crecieron durante el periodo, aunque las transfe- rencias lo realizaron a un mayor ritmo que los recursos propios. (p. 41)

\section{Fuentes de financiación de las entida- des territoriales}

De acuerdo con el Estatuto Orgánico del Presupuesto (Decreto 111 de 1996), el presupuesto general de las entidades territoriales ${ }^{4}$, para el caso de los distritos o municipios, se distribuye de la siguiente manera (Figura 1):

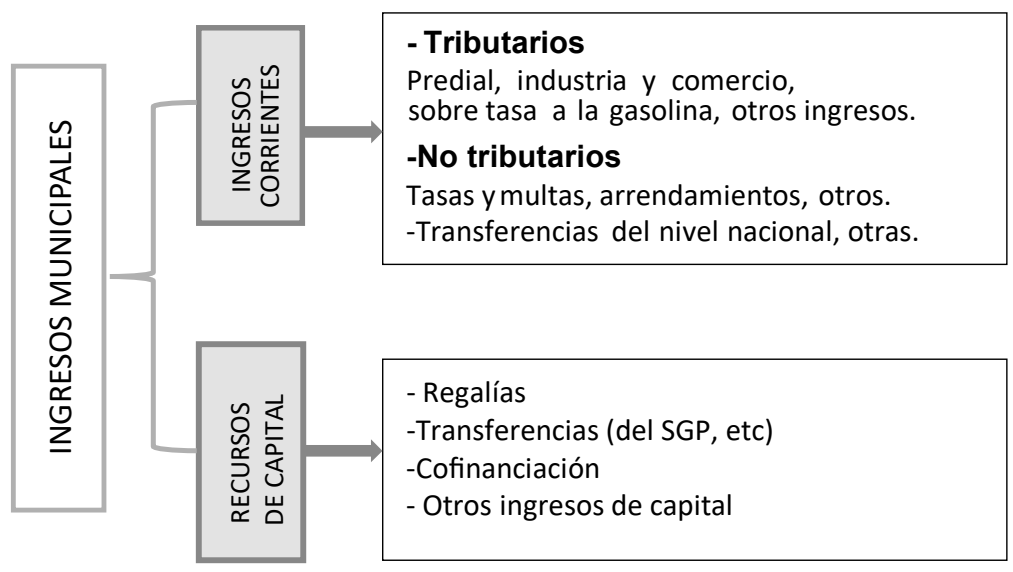

Figura 1. Clasificación de los ingresos municipales

Como se puede observar en la Figura 1, las fuentes de financiación de los municipios se dividen en dos:

a. Ingresos corrientes, los cuales son recibidos por los municipios de manera regular y corresponden a funciones y competencias de cada entidad territorial. Entre ellos se encuentran los ingresos tributarios y no tributarios.

b. Recursos de capital: son aquellos percibidos por regalías, transferencias y recursos de cofinanciación, entre otros.

3 Gobiernos subnacionales.

4 El esquema de ingresos para los departamentos es el mismo que el de los municipios, sin embargo, se deben distinguir los tipos de ingresos tributarios que recibe cada uno. 
Respecto a los recursos provenientes del Sistema General de Regalías ${ }^{5}$, se establece que son ingresos recibidos como contraprestación económica al Estado producto de la explotación de recursos naturales, sobre los cuales las entidades territoriales tienen derecho y deben ser utilizados para el financiamiento de proyectos para el desarrollo social, económico y ambiental de dichos entes; ahorro para pasivo pensional, inversiones físicas en educación, inversiones en ciencia, tecnología e innovación; generación de ahorro público; fiscalización de la exploración y explotación de yacimientos, cartografía geológica, entre otros, y para mejoras en la competitividad de la economía en busca de mejores condiciones sociales para la población (Departamento Nacional de Planeación [DNP], 2018).

Los recursos provenientes del Sistema General de Participaciones (SGP) se deben distribuir de la siguiente manera ${ }^{6}$ :

- Participación con destinación específica: educación y salud $(58.5 \%$ y $24.5 \%$ respectivamente).
- Participación de propósito general: servicios públicos, vivienda de interés social, sector agropecuario, cultura, deporte, entre otras (17\%).

\section{Categorización territorial}

En el capítulo 1 de la Ley 617 del año 2000 se presenta la categorización de las entidades territoriales, el artículo 2 corresponde a la categorización de los distritos y municipios, y establece que la clasificación de estos se lleva a cabo atendiendo a su población e ingresos corrientes de libre destinación 7 . La Ley 617 determina una categoría especial $\mathrm{y}$ seis adicionales, que para el caso de estudio, los municipios de sexta categoría son: "Todos aquellos distritos o municipios con población igual o inferior a diez mil (10.000) habitantes y con ingresos corrientes de libre destinación anuales no superiores a quince mil (15 000) salarios mínimos legales mensuales" (Ley 617 de 2000). De acuerdo con esta norma, la clasificación de los municipios de Colombia, al cierre de la vigencia 2018, es la siguiente:

$5 \quad$ Creado por medio del Acto Legislativo 05 de 2011.

6 Se deducirá un $4 \%$ anual del total del SGP, destinado a: resguardos indígenas (0.52 \%), Fondo Nacional de Pensiones de las Entidades Territoriales (2.9\%), municipios que limiten con el río Magdalena $(0.08 \%)$, y alimentación escolar (0.5\%) (Ley 715 de 2001).

7 A efectos de lo dispuesto en esta ley, se entiende por ingresos corrientes de libre destinación los ingresos corrientes, excluidas las rentas de destinación específica; y estas son las destinadas por ley o acto administrativo a un fin determinado (Ley 617 de 2000, art. 3, parágrafo 1). 


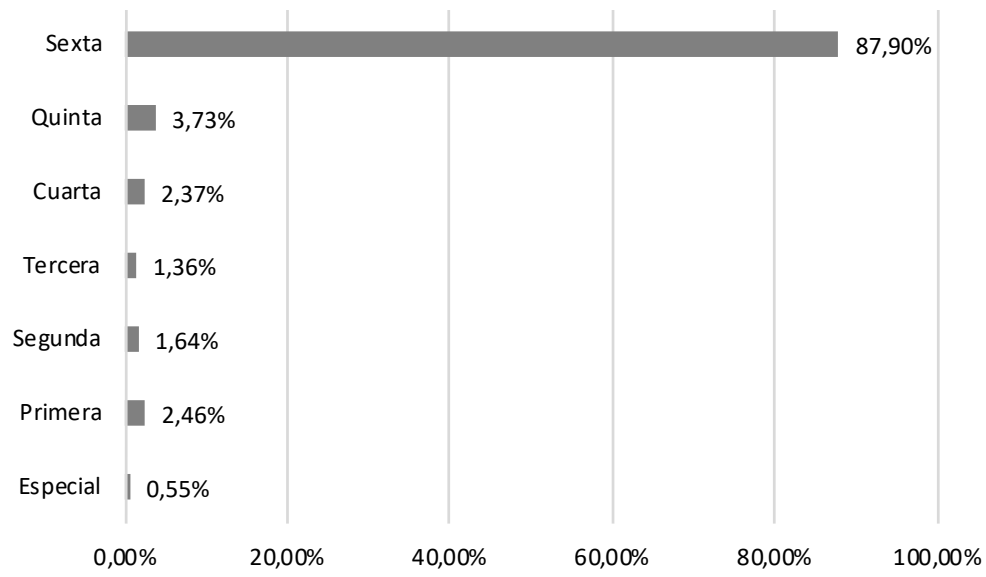

Figura 2. Clasificación de los municipios de Colombia, según categorías establecidas por la Ley 617 de 2000

Estos criterios de clasificación determinan que cerca del $90 \%$ de los municipios de Colombia estén clasificados en sexta categoría, lo que los hace más vulnerables a la dependencia fiscal, dada su baja capacidad de generación de rentas propias. Situación que justifica que sean objeto de estudio del presente artículo.

\section{EVOLUCIÓN DE LA GESTIÓN FINANCIERA DE LOS MUNICI- PIOS COLOMBIANOS DE SEXTA CATEGORÍA}

Considerando la clasificación antes citada, a continuación se presenta el análisis sobre las condiciones fiscales y el nivel de dependencia que tienen actualmente los municipios de sexta categoría de
Colombia, con base en el cálculo de algunos indicadores de gestión financiera establecidos por el DNP ${ }^{8}$, obtenidos para cada uno de los 966 municipios de sexta categoría del país, según la información de las operaciones efectivas de caja (en pesos constantes) reportadas por cada ente territorial al DNP durante el periodo 2000-2016 ${ }^{9}$. Una vez calculados los indicadores individualmente para cada municipio, se establece el promedio del indicador con el fin de poder realizar el análisis global.

Estos indicadores de gestión financiera servirán de base más adelante para el cálculo y el análisis de algunas estimaciones econométricas.

$8 \quad$ Para tal fin se siguió el Manual de técnicas para el análisis de la gestión financiera de las entidades territoriales, del Departamento Nacional de Planeación (DNP, 2008).

9 Cabe anotar que el DNP no reporta la información de las OEC para todos los municipios de Colombia durante el periodo de estudio, pues para algunos de ellos no se registran datos porque no fueron reportados o por la creación reciente del ente territorial. 
Participación de los impuestos en los ingresos totales y corrientes de los municipios

Este indicador se determina con el fin de cuantificar el porcentaje de participación que tienen los ingresos tributarios dentro de los ingresos corrientes e ingresos totales de cada ente territorial, de manera que se pueda establecer que, a mayor porcentaje de participación, mayor es el esfuerzo que realiza el municipio por autofinanciarse. Se calcula a partir de la siguiente fórmula (DNP, 2008):

Participación porcentual $=[($ Ingresos tributarios /_Ingresos totales o corrientes) $\mathrm{x} 100]$
Con relación a la participación de los impuestos en los ingresos totales (Figura 2), los resultados del indicador muestran que, en promedio, en los municipios de sexta categoría esta participación oscila entre el $8.9 \%$ (2000) y el $14.27 \%$ (2016), y presenta una tendencia creciente durante el periodo de estudio, pero a un ritmo muy bajo, lo que significa que la capacidad de generar recursos propios vía impuestos (predial, industria y comercio y sobretasa a los combustible, primordialmente), es limitada para estos entes territoriales. Hecho que implica que deban percibir sus ingresos de otras fuentes, entre ellas, prioritariamente, las transferencias, como se verá más adelante.

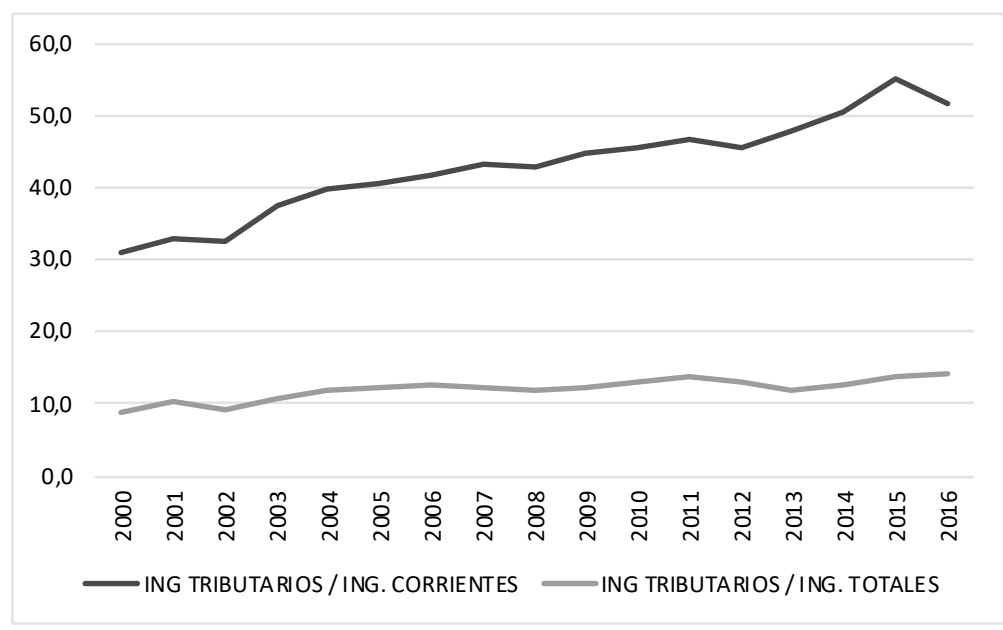

Figura 3. Participación porcentual de los ingresos tributarios en los ingresos totales y corrientes, para los municipios de sexta categoría de Colombia

Por su parte, la participación de los ingresos tributarios dentro de los ingresos corrientes de los municipios de sexta categoría presenta una mayor proporción, que oscila entre el 31.01\% (2000) y 55.11\% (2015), ganando participación 
a lo largo del periodo de referencia, pero sin superar la mitad de las fuentes de origen de los recursos clasificados como ingresos corrientes, que son los que le aseguran mayor estabilidad de financiación a los municipios.

De los indicadores antes revisados se puede establecer que, si bien es cierto que las participaciones que alcanzan los ingresos tributarios en los ingresos corrientes tienen un nivel cercano al $50 \%$, son muy bajas cuando se comparan con los ingresos totales. Lo que muestra que también los ingresos corrientes presentan una reducida participación en los ingresos totales de los municipios, hecho que refuerza el alto nivel de dependencia fiscal que ellos registran, máxime cuando la capacidad de generación de tributos es limitada debido, entre otras razones, al rezago catastral que sirve de base para el cobro del impuesto predial y a la estrechez de las economías locales, sobre todo en términos de actividades de transformación, aunado al bajo nivel de formalización de las existentes, lo que se ve reflejado en una escasa tributación por concepto de industria y comercio (Delgado \& Acero, 2015). Comenzar el proceso de actualización del catastro, especialmente en el área rural, así como aumentar la tarifa de industria y comercio para actividades de cubrimiento nacional como las telecomunicaciones, lograrían aumentar los recaudos territoriales.

\section{Grado de esfuerzo fiscal y nivel de de- pendencia fiscal}

Cuando se habla de esfuerzo fiscal, se busca establecer si "la entidad territorial está realizando esfuerzos dentro de su administración para aumentar el recaudo por impuestos" (DNP, 2008, p. 46). De manera que, si se obtiene un resultado positivo entre una vigencia fiscal y la anterior, es un indicador de que la administración territorial realizó un esfuerzo fiscal por incrementar el recaudo real entre dos años consecutivos, mejoró su autonomía fiscal y contrarrestó la dependencia fiscal. El indicador de esfuerzo fiscal se construye así:

$$
\Delta Y_{t}=\left[\left(Y_{t} / Y_{t-1}\right)-1\right]^{*} 100
$$

Donde $\Delta \mathrm{Y}_{\mathrm{t}}$ es la variación marginal en el recaudo (esfuerzo fiscal), $Y_{t}$ es el nivel del recaudo en el periodo $t$ y $Y_{t-1}$ es el recaudo en el periodo inmediatamente anterior (DNP, 2008).

La Figura 4 muestra cómo ha evolucionado el nivel de esfuerzo fiscal en los municipios de sexta categoría en Colombia, el cual, en términos generales, muestra una tendencia decreciente, pues si bien es cierto que logra valores del $68.58 \%$ (2003) o $43.12 \%$ (2012), durante la mayor parte de los años revisados se evidencia que los entes territoriales han venido reduciendo su capacidad de incrementar los ingresos tributarios entre una vigencia y la anterior, especialmente del 2014 en adelante. 


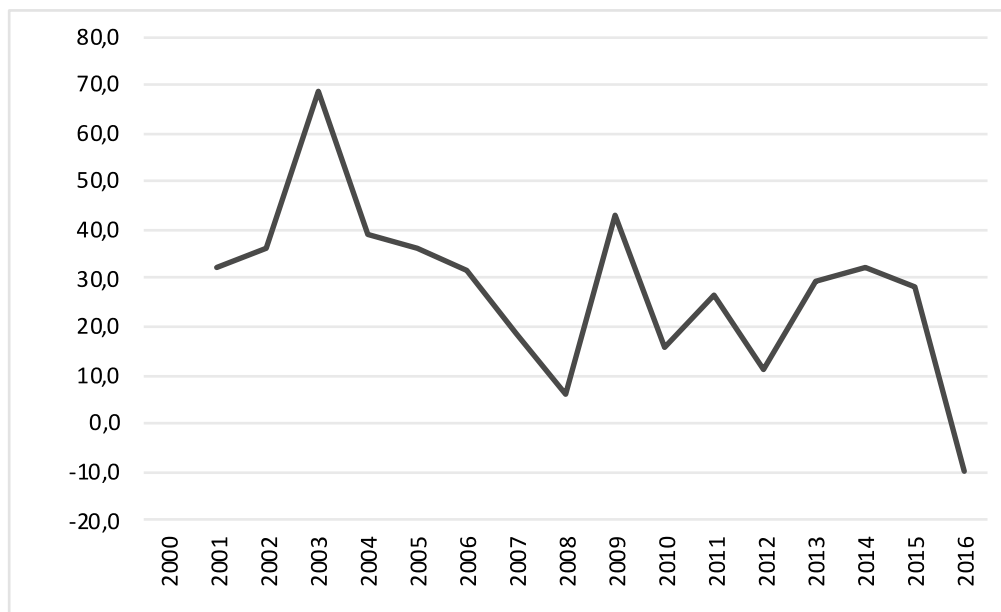

Figura 4. Nivel de esfuerzo fiscal para los municipios de sexta categoría de Colombia

Ese bajo nivel de esfuerzo fiscal puede radicar en el relativo estancamiento de las fuentes de tributación que tienen los municipios, lo que hace que el recaudo evolucione poco en términos reales y, por tanto, el esfuerzo por aumentar los recaudos se oriente casi siempre a actividades de fiscalización, mediante el adelanto de procesos de cobro coactivo de impuestos.

Complementariamente, el otro indicador que ha de tenerse en cuenta es aquel que determina el grado de dependencia fiscal, en particular frente a la dependencia de los recursos provenientes del Sistema General de Participaciones (SGP), ya que con él se logra determinar el "grado de dependencia que presenta la administración territorial de los recursos provenientes del Sistema General de Participaciones, así como el análisis de su evolución en un período determinado" (DNP, 2008, p. 51), lo que posibilita identificar situaciones que pueden explicar el fortalecimiento o debilitamiento de la capacidad del municipio para generar mayores recursos propios provenientes de mayor tributación, por ejemplo, ya sea que las transferencias del SGP disminuyan o se incrementen. El indicador de dependencia fiscal del SGP se calcula así (DNP, 2008):

$$
\begin{gathered}
\text { Dependencia fiscal del SGP }=[(\text { Monto } \\
\text { de recursos del SGP recibidos } / \text { Total } \\
\text { de ingresos) } \text { x 100] }
\end{gathered}
$$

Así, a mayor valor del indicador, mayor será el nivel de dependencia fiscal que tiene el ente territorial. La evolución de las transferencias también se puede analizar con base en el cálculo de su variación marginal (entre dos vigencias 
fiscales seguidas), utilizando el indicador calculado para el esfuerzo fiscal.

Los valores indican que el nivel de dependencia fiscal de los municipios objeto de estudio se ha mantenido elevado a lo largo de todo el periodo, siendo el más bajo en el año 2015 $(51,48)$ y el más alto en el 2008 $(62,52)$, mientras que en los demás años ha variado acorde con los ajustes normativos que se han implementado al respecto, así como la gestión tributaria de los municipios. Hechos estos que no han impactado de forma sustancial la dependencia fiscal, lo que significa que casi dos terceras partes de los ingresos de estos entes territoriales provienen del gobierno central.

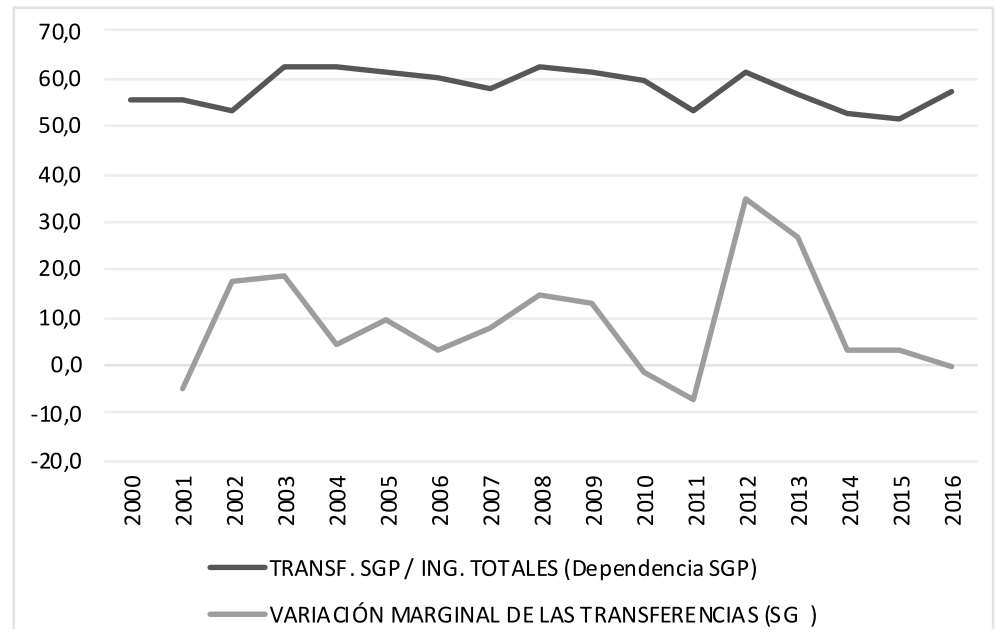

Figura 5. Nivel de dependencia fiscal y variación marginal de las transferencias (SGP) para los municipios de sexta categoría de Colombia

También en la Figura 5 aparece la variación interanual de las transferencias, indicador que varía considerablemente durante los años de estudio, pues así como estas aumentan un $34.83 \%$ (2012), también caen un $-7.01 \%$ (2011), mientras que en las otras vigencias se registran variaciones menores, generadas quizá por los cambios normativos introducidos al SGP o por ajustes en los factores que determinan la distribución de estos recursos para ser trasladados a los mu- nicipios. En suma, durante el periodo de estudio la variación de las transferencias fue en promedio del $8.95 \%$, en tanto que el nivel de dependencia fiscal fue en promedio del $58.02 \%$.

Este panorama implica una fuerte dependencia de los gobiernos locales hacia el gobierno central, ya que, no obstante estar reglamentada normativamente la distribución y asignación de las transferencias, ellas constituyen 
un instrumento de injerencia política sobre los gobiernos subnacionales, los que deben responder a la lógica de los ciclos político-electorales (Delgado \& Acero, 2015).

La disparidad de comportamiento entre el esfuerzo fiscal y la dependencia fiscal (Figura 6) se hace evidente al comparar la evolución de ambos indicadores, que muestran tendencia contraria en varios años, ya que en la medida en que el esfuerzo fiscal de los municipios sea menor, es decir, se logre un menor crecimiento en sus ingresos tributarios, mayor será el grado de dependencia fiscal y menor será la capacidad de disponer de recursos propios para orientarlos de manera autónoma a las necesidades de inversión que priorice la administración local, frente a la destinación específica que posee la mayor parte de los dineros transferidos desde una instancia de gobierno superior.

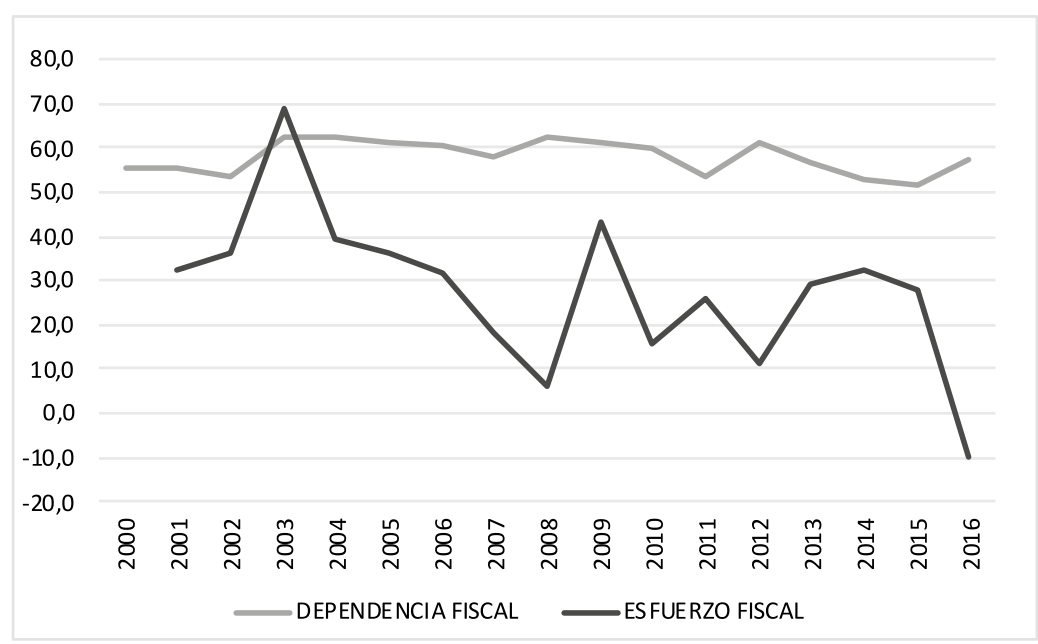

Figura 6. Nivel de dependencia fiscal y de esfuerzo fiscal para los municipios de sexta categoría de Colombia

\section{Indicadores de gasto e inversión}

El análisis se centra ahora en la revisión del comportamiento de dos tipos de gastos realizados por los municipios de sexta categoría de Colombia: los gastos de funcionamiento y los gastos de inversión.
Los gastos de funcionamiento son aquellos en que incurren los municipios para cumplir normal y adecuadamente con las funciones que les han sido asignadas por la ley (Herrera, 2003), y comprenden los rubros de servicios personales (pagos de personal), gastos generales, gastos de operación y transferencias. 
Por su parte, los gastos de inversión corresponden a los recursos apropiados para atender los planes y proyectos contemplados en el Plan Operativo Anual de Inversión (POAI), y pueden estar orientados a infraestructura física o formación bruta de capital fijo (carreteras, puentes, edificios, etc.), desarrollo económico (fomento de actividades productivas) y desarrollo social (salud, educación, agua potable, vivienda, etc.) (Herrera, 2003).

Al aplicar los criterios de evaluación de la gestión financiera de los municipios, tal y como lo ha establecido el DNP, al comportamiento presentado por los gastos de funcionamiento, se debe establecer, en primera instancia, el porcentaje de los ingresos corrientes de libre destinación ${ }^{10}$ (ICLD) que cada ente territorial utiliza para cubrirlos (DNP, 2008). De acuerdo con lo establecido en el artículo 6..$^{\circ}$ de la Ley 617 de 2000, el valor máximo de los gastos de funcionamiento de los municipios de sexta categoría no puede superar el $80 \%$ de los ingresos corrientes de libre destinación, para lo cual se fijó un periodo de transición para implementar ese ajuste desde el año 2001 al 2004, comenzando con un máximo del $95 \%$ y cerrando con el $80 \%$ exigido, de manera que de ese año en adelante se debería mantener el cumplimiento de la meta. Para revisar el cumplimiento de este mandato legal se construyó el siguiente indicador (DNP, 2008):

Participación Gastos de funcionamiento en los ICLD $=[($ Gastos de Funcionamiento / ICLD) x100]

En los municipios objeto de estudio se encuentra que los gastos de funcionamiento absorben una buena parte de los ingresos corrientes de libre destinación, durante todo el periodo analizado (Figura 7). Esta participación porcentual empezó sobrepasando incluso el nivel de los ICLD en el año 2000, pero a partir de ese año, una vez promulgada la Ley 617 de 2000, los municipios se vieron obligados a ir reduciendo los gastos de funcionamiento para ajustarlos al máximo permitido por la norma. Así, desde el año 2001 comienza a reducirse, hasta llegar al $61.63 \%$ en 2010 , se eleva un poco al año siguiente $(64.35 \%)$ y continúa bajando hasta el año 2015 (53.58 \%), para cerrar el periodo de estudio con un leve incremento en 2016.

El anterior comportamiento muestra que los municipios de sexta categoría del país han hecho un esfuerzo por restringir sus gastos de funcionamiento, liberando recursos para orientarlos hacia la inversión, producto de la gestión financiera que han hecho, en buena parte compelidos por la restricción impuesta por las normas de sostenibilidad fiscal que se han expedido.

10 El parágrafo 1 del artículo 3 de la Ley 617 de 2000, define los ingresos corrientes de libre destinación como aquellos ingresos corrientes, excluidas las rentas de destinación específica, entendiendo por estas las destinadas por ley, ordenanzas, acuerdos o cualquier acto administrativo a un fin determinado de carácter municipal o departamental (DNP, 2008). 


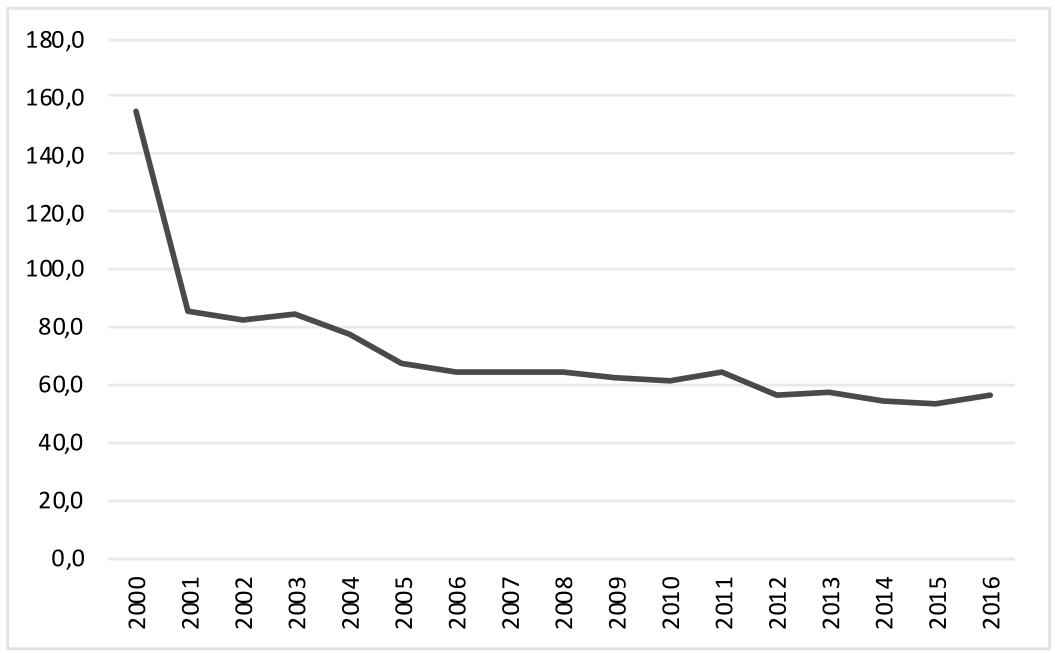

Figura 7. Participación porcentual de los gastos de funcionamiento en los ICLD para los municipios de sexta categoría de Colombia

Sin embargo, como los ICLD están compuestos principalmente por tributos, el esfuerzo fiscal que pudieran realizar los gobiernos municipales se orienta, en buena proporción, para operar administrativamente, de manera que los recursos que aportan los ciudadanos a sus gobiernos locales, vía tributación, les son devueltos principalmente con los servicios que pueda prestar la administración pública que funciona gracias a tales impuestos, en tanto que una menor parte de los mismos podrá ser dirigida a financiar inversiones que favorezcan las condiciones de vida de las comunidades.

Además, el tope máximo introducido por la Ley 617 de 2000 hace que los gobiernos municipales tengan que contraer sus gastos de funcionamiento a lo mínimo requerido, o menos, o para mantenerse operando deben acudir a los recursos de las transferencias del SGP, componente Propósito General (que representa el 17\% del SGP), pues la Ley 715 de 2001 en su artículo 78 reglamentó que los municipios de 4. . $^{\mathrm{a}}$ 5. $\mathrm{y}$ 6. ${ }^{a}$ categoría podían destinar libremente hasta el $28 \%$ de los recursos de este componente a la financiación de gastos de funcionamiento o inversión. Es decir, que el Legislativo a través de la Ley 617 obliga a los municipios a reducir los gastos de funcionamiento, los cuales se financian con los ICLD, pero con la Ley 715 le otorga los recursos para compensar tal reducción, manteniendo similares niveles de gastos de funcionamiento, solo que ahora algunos de ellos aparecen registrados como inversión.

Revisando ahora lo relacionado con los gastos de inversión, para su análisis se 
calcularon dos indicadores, participación porcentual de los gastos de inversión en el gasto total y la participación porcentual de la formación bruta de capital fijo (FBKF) y de la inversión social en la inversión total, con base en las siguientes fórmulas:

Participación Gastos de inversión en gasto total $=[($ Gastos de Inversión /

Gasto Total) x100]

Participación Inversión en FBKF en inversión total $=[($ Inversión en FBKF $/$ Inversión Total) x100]

Participación Inversión Social en inversión total $=[($ Inversión en FBKF $/$ Inversión Total) x100]
La inversión, como proporción del total de gastos en los municipios de sexta categoría de Colombia, presenta un comportamiento ascendente a lo largo del periodo de estudio, al inicio representa el $67.62 \%$ del gasto total, llega hasta el $88.96 \%$ en 2015 y muestra una tendencia de crecimiento un poco más acentuada de 2000 al 2003. Tal comportamiento obedece a la promulgación de las leyes 617 de 2000 y 715 de 2001, así como a la estructuración del SGP y el Fondo Nacional de Regalías, lo que generó permanencia y estabilidad a la disponibilidad de recursos para invertir, pero, al ser la mayor fuente de financiación de la inversión, esto hace que las posibilidades de ampliación de la misma sean muy limitadas, ya que eso dependerá de la generación de recursos propios por parte de los entes territoriales.

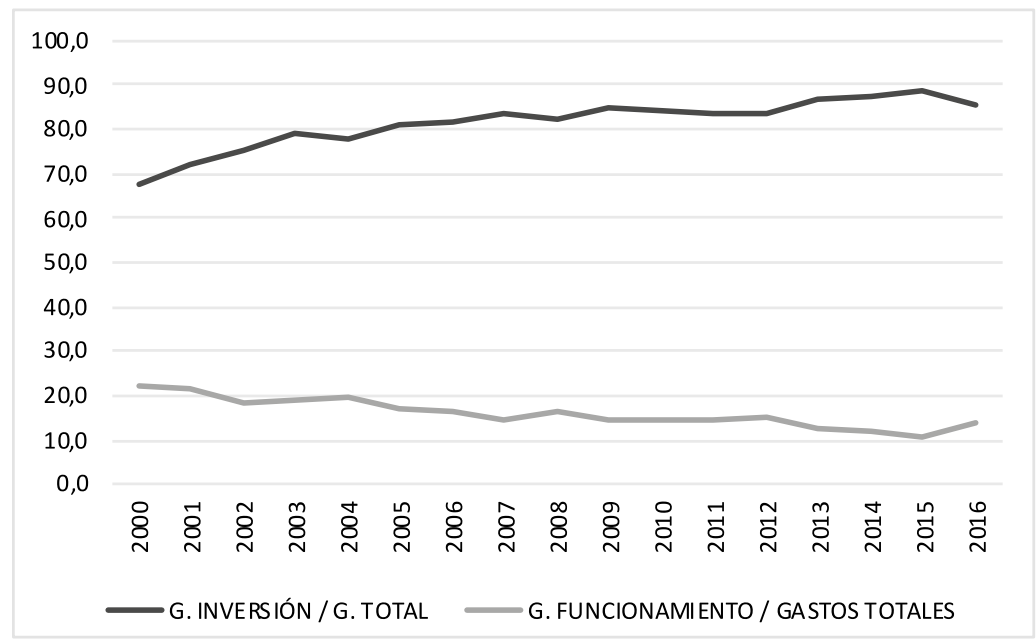

Figura 8. Participación porcentual de los gastos de inversión y de los gastos de funcionamiento en los gastos totales de los municipios de sexta categoría de Colombia 
Por su lado, los gastos de funcionamiento, que son la contraparte de los gastos de inversión dentro de los gastos totales de los municipios, han venido reduciendo su participación, desde el $22.31 \%$ en el año 2000 hasta llegar al $10.52 \%$ en 2015 , gracias al ajuste fiscal exigido por la Ley 617 de 2000.

$\mathrm{Y}$ en lo concerniente a la participación de la inversión en FBKF (infraestructura física) y la inversión social dentro de la inversión total (Figura 9), es preciso señalar que la inversión social estuvo por arriba de la inversión en FBKF durante la mayor parte del periodo de análisis, superándola entre un $35 \%$ y $80 \%$, a excepción de los años 2012, 2013 y 2014, cuando solo representó alrededor de una tercera parte de la primera, lo que implica que para los gobiernos locales siempre se ha privilegiado la inversión social a la hora de establecer la orientación de la inversión, en buena medida porque la dependencia fiscal hace que la inversión sea financiada primordialmente con recursos transferidos desde otros niveles de gobierno, recursos que tienen destinación específica, prefiriendo la atención de necesidades básicas mediante la inversión social. Es por eso que el repunte de la inversión en FBKF ocurrida durante los tres años ya señalados se debe a la entrada en vigencia del nuevo sistema general de regalías, que orientó recursos a financiar proyectos de infraestructura física en varias regiones del país.

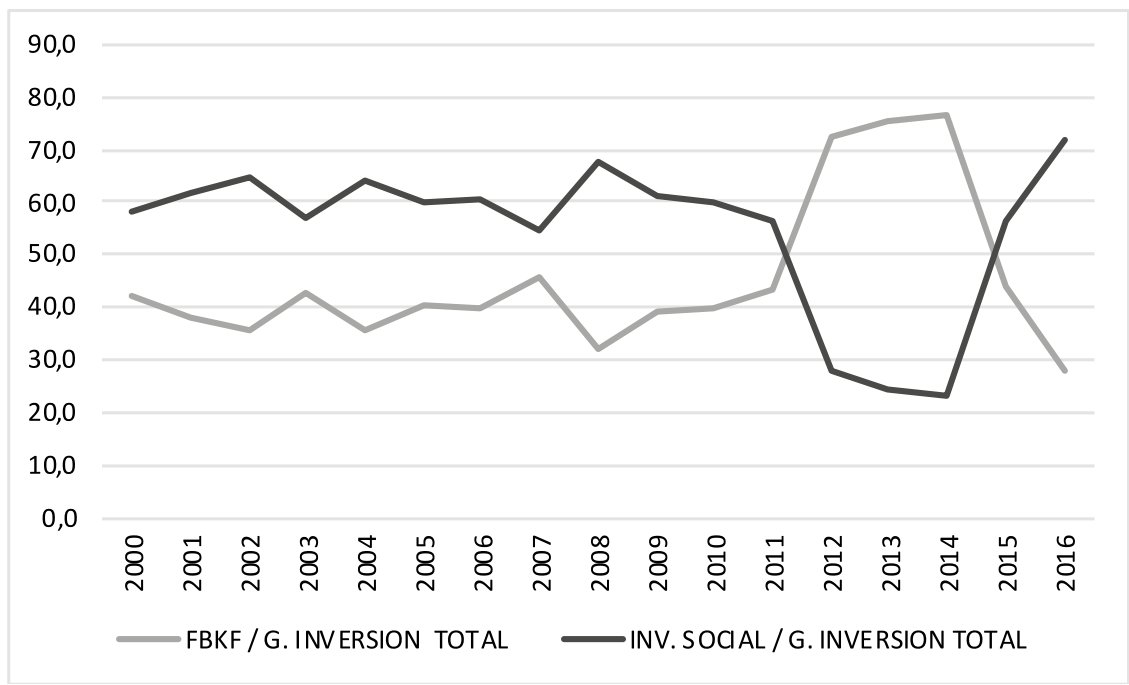

Figura 9. Participación de los gastos de inversión en FBKF e inversión social en los gastos de inversión de los municipios de sexta categoría de Colombia 
La dependencia en la financiación de la inversión también se observa cuando se calcula el nivel de autofinanciamiento de la inversión para los municipios de interés. Tal grado de autofinanciamiento indica "la proporción del ahorro que se utiliza en pagos de inversión, es decir, el grado de autofinanciamiento (apalancamiento) que la entidad territorial tiene para cubrir pagos de inversión" (DNP, 2008, p. 57) y se calcula así:

\section{Autofinanciamiento de la Inversión $=[($ Ahorro Corriente $/$ Gasto de Inversión) x100]}

La evolución de este indicador (Figura 10) muestra un ritmo ascendente al inicio del periodo de referencia, entre los años 2000 y 2007, incrementándose de niveles del $2.98 \%$ hasta alcanzar el
$30.48 \%$, para luego caer y estabilizarse en un rango entre el $10 \%$ y el $11 \%$, salvo en el año 2016 que sube al $14.46 \%$. El dato elevado del indicador en el año 2007 se debe a una reducción en el ritmo de crecimiento de los gastos de inversión en esa vigencia.

Este bajo nivel de autofinanciamiento de la inversión se puede relacionar con el grado de dependencia fiscal que tienen los municipios de referencia, ya que en la medida en que el ente territorial no sea capaz de generar recursos para acometer las inversiones que la comunidad requiere, tendrá que depender del giro de recursos del gobierno central para poder así ejecutar algunas inversiones, muchas de ellas determinadas por el nivel de gobierno que otorga las transferencias.

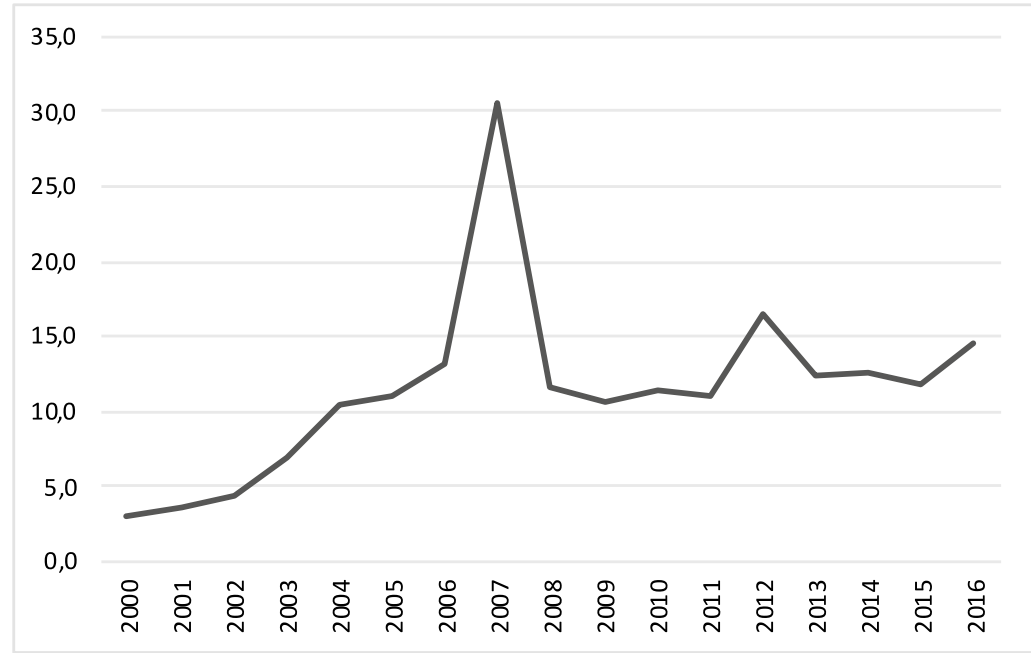

Figura 10. Nivel de autofinanciamiento de la inversión (ahorro corriente) para los municipios de sexta categoría de Colombia 
Dicha situación se evidencia al cruzar en la Figura 11 los niveles de dependencia fiscal y de autofinanciamiento de la inversión, pues se encuentra una relación inversa entre estos para la mayor parte de los años del periodo de estudio, de manera que, a menor auto- financiamiento de la inversión, mayor grado de dependencia fiscal. Cobra acá relevancia la afirmación de Roth (2017) ,en cuanto que "El alcalde no decide realmente, sino que ratifica decisiones impuestas desde afuera" (p. 159).

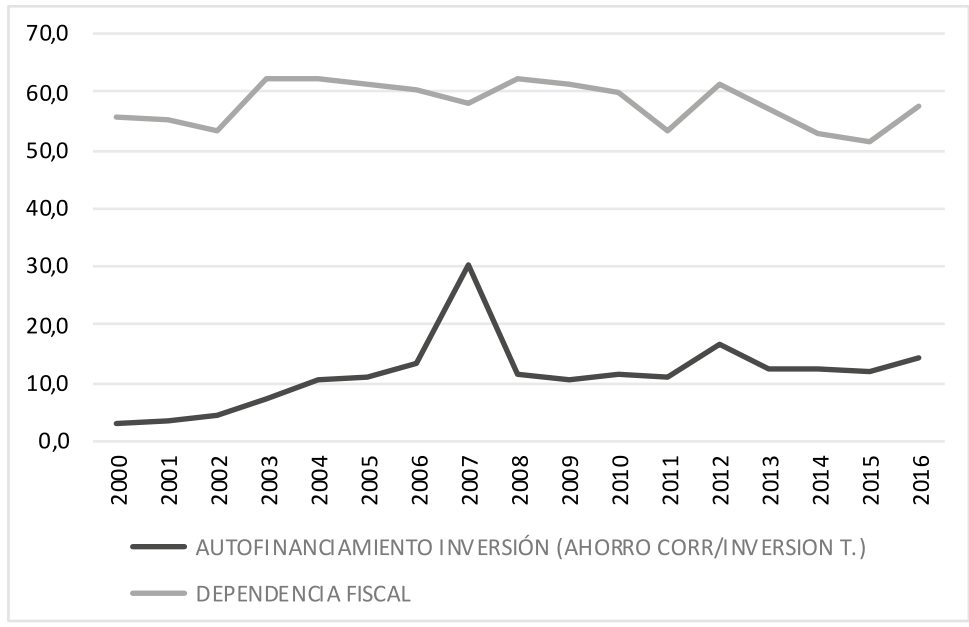

Figura 11. Nivel de dependencia fiscal frente al nivel de autofinanciamiento de la inversión (ahorro corriente/inversión total) para los municipios de sexta categoría de Colombia

ESTIMACIÓN DEL COMPORTAMIENTO DE LA DEPENDENCIA FISCAL DE LOS MUNICIPIOS COLOMBIANOS DE SEXTA CATEGORÍA

Al relacionar los planteamientos de orden teórico esbozados al comienzo, así como los resultados de la evolución de los indicadores de gestión financiera calculados y analizados en el acápite anterior, a continuación se plantea un ejercicio econométrico con el fin de establecer las variables que inciden en el nivel de dependencia fiscal de los municipios objeto de estudio, así como cuantificar el posible impacto de cada una de estas. La idea detrás de este ejercicio es corroborar si la dependencia fiscal, medida mediante una variable proxy construida a través del peso de las transferencias dentro de los ingresos corrientes de los municipios del país, tiene algún tipo de relación directa o indirecta con variables relacionadas, como las mismas transferencias, los ingresos tributarios, gastos de funcionamiento, necesidades básicas insatisfechas, y variables de orden político como años de elecciones locales y nacionales. Esta ecuación se basa en 
el estudio de Delgado \& Acero (2015), quienes estiman la dependencia fiscal para el departamento de Boyacá con un método de datos agrupados, y quienes corroboran la hipótesis de dependencia para municipios de categoría seis.

A diferencia del modelo estimado por Delgado \& Acero (2015), se utiliza un método de datos tipo panel por efectos fijos y aleatorios, y se verifican posibles problemas de endogeneidad entre dependencia fiscal y variación de transferencias. Esta verificación se hizo a partir del test de Hausman para endogenidad, el cual validó la no existencia del problema y en consecuencia evitar el posible sesgo de los errores. La construcción de la ecuación estimada parte de considerar que la dependencia fiscal puede medirse desde el punto de vista de qué tanto participan las transferencias de la nación a los municipios dentro del total de sus ingresos, es decir, a mayor participación, mayor es el grado de dependencia y viceversa. Dicha variación se espera que sea inversa a medida que el municipio incrementa su recaudo tributario propio, o a medida que logra una disminución de sus gastos de funcionamiento, igualmente a medida que logra un mayor autofinanciamiento de la inversión que realiza. Una mayor población del municipio, y mayores necesidades básicas por atender, deberían incrementar la dependencia de los municipios por la mayor demanda de servicios por cubrir. Componentes de carácter político siempre afectan los ingresos municipales y en consecuencia los cambios de administración local y nacional deben considerarse para evitar problemas de especificación.

\section{Modelo econométrico}

En este orden de ideas, y con el fin de obtener una explicación coherente de la dependencia fiscal municipal, se estimó un modelo de datos panel. Esta metodología combina datos de series de tiempo y de cortes transversales y, en consecuencia, permite manejar una mayor cantidad de información y posibilita un mejor tratamiento del problema de variable omitida. Un modelo de datos panel puede ser estimado inicialmente a través de una modelación de datos agrupados; no obstante, si el método utilizado corresponde a una estimación de mínimos cuadrados ordinarios, se estaría asumiendo que no hay variables importantes fuera del modelo. Precisamente, la ventaja de abordar este problema y modelarlo, ya sea a través de la eliminación de esta variable por efectos fijos o de un tratamiento especial para los errores del modelo por medio de efectos aleatorios, permite la obtención de resultados robustos y consistentes. La siguiente ecuación representa un modelo de datos panel para explicar la dependencia fiscal en Colombia para el periodo 2000-2016. 


$$
\begin{gathered}
\text { lnDependencia }=\alpha+\beta_{1 i t} \Delta T r+\beta_{2 i t} \ln \left(\frac{\text { Trib }}{\text { ingT }}\right)+\beta_{3 i t} \ln \left(\frac{\text { Fin }}{\text { ingT }}\right)+\beta_{4 i t} \text { Auto }+ \\
\beta_{5 i t} \operatorname{lnPob}+\beta_{6 i t} \text { DummyPresidente }+\beta_{7 i t} \text { DummyAlcalde }+\beta_{8 i t} \ln N B I+\mu_{i t}
\end{gathered}
$$

Para la ecuación anterior, InDependencia representa el logaritmo natural, la participación porcentual de las transferencias dentro de los ingresos totales del municipio; $\ln \left(\frac{\text { Trib }}{\text { ingT }}\right)$ el logaritmo natural de los ingresos tributarios sobre los ingresos totales; $\ln \left(\frac{G F}{i n g T}\right)$ el logaritmo natural de los gastos de funcionamiento sobre los ingresos totales; Auto es una variable para el autofinanciamiento de la inversión; lnPob logaritmo natural de la población; DummyAlcalde variable dicótoma con 1 para los años con elección de alcaldes; DummyPresidente variable dicótoma con 1 para los años con elección de presidente; lnNBI logaritmo natural del índice de necesidades básicas insatisfechas.

\section{Resultados}

A continuación se presentan las salidas econométricas de los modelos estimados para el período seleccionado. El primer modelo se estimó por mínimos cuadrados agrupados y se contrastó con una estimación por efectos aleatorios y efectos fijos. Es de mencionar que el test de Hausman sugiere una estimación de efectos aleatorios por sobre los efectos fijos, aunque como se evidencia en las salidas econométricas, no hay una variación sustancial en el valor de los coeficientes de los tres modelos y en su significancia estadística, excepto para el logaritmo natural de las NBI y para las dummies de presidente y alcalde que no aplican para la estimación de efectos fijos.

Tabla 1. Resultados econométricos por MCA, EF y EA

\begin{tabular}{cccc}
\hline & Modelo 1 & Modelo 2 & Modelo 3 \\
\cline { 2 - 4 } & MCA & E-aleatorios & E-fijos \\
\hline VARIABLES & InDependencia & InDependencia & InDependencia \\
\hline$\Delta$ TR & $6.98 \mathrm{e}-05^{* * *}$ & $6.81 \mathrm{e}-05^{* * *}$ & $6.75 \mathrm{e}-05^{* * *}$ \\
\hline InTrib/ingT & $(0.0000)$ & $(0.0000)$ & $(0.0000)$ \\
\hline LnGF/ingT & $-0.109^{* * *}$ & $-0.112^{* * *}$ & $-0.114^{* * *}$ \\
\hline & $(0.0031)$ & $(0.0031)$ & $(0.0031)$ \\
\hline Auto & $0.190^{* * *}$ & $0.192^{* * *}$ & $0.194^{* * *}$ \\
\hline InPob & $(0.0067)$ & $(0.0070)$ & $(0.0072)$ \\
\hline & 0.00002 & 0.00001 & 0.0000 \\
\hline Dummypresidente & $(0.0000)$ & $(0.0000)$ & $(0.0000)$ \\
\hline & $0.0518^{* * *}$ & $0.0529^{* * *}$ & $0.0535^{* * *}$ \\
\hline Dummyealcalde & $(0.0032)$ & $(0.0032)$ & $(0.0031)$ \\
\hline & $-0.0559^{* * *}$ & $-0.0563^{* * *}$ & - \\
\hline
\end{tabular}


Continuación Tabla 1

\begin{tabular}{cccc}
\hline & Modelo 1 & Modelo 2 & Modelo 3 \\
\cline { 2 - 4 } & MCA & E-aleatorios & E-fijos \\
\hline InNBI & $(0.0057)$ & $(0.0101)$ & \\
\hline & $0.0122^{* *}$ & $0.00940^{* *}$ & $0.00795^{*}$ \\
\hline Constant & $(0.0048)$ & $(0.0047)$ & $(0.0047)$ \\
\hline & $2.999^{* * *}$ & $2.996^{* * *}$ & $2.954^{* * *}$ \\
\hline Observations & $(0.0400)$ & $(0.0408)$ & $(0.0408)$ \\
\hline R-squared & 13351.0000 & 13351.0000 & 13351.0000 \\
\hline & 0.2190 & & 0.2000 \\
\hline & Standard errors in parentheses \\
\hline
\end{tabular}

\section{Discusión de resultados}

De las salidas econométricas se puede observar que, para los tres modelos estimados por mínimos cuadrados agrupados, efectos aleatorios y efectos fijos, los coeficientes son significativos para la variación marginal de transferencias, el logaritmo natural de la relación de los ingresos tributarios sobre los totales, el logaritmo natural de la relación de gastos de funcionamiento sobre los ingresos totales, el logaritmo de la población, así como el de las necesidades básicas insatisfechas y las dummies para elección de presidente y de alcaldes.

Del mismo modo, se evidencia coherencia en los signos esperados, ya que se observa que la variación marginal de las transferencias, así como la relación entre los gastos de funcionamiento y los ingresos totales, población y necesidades básicas insatisfechas, incrementan la dependencia fiscal, en tanto que la relación entre los ingresos tributarios sobre los ingresos totales, así como las dummies para los años en los que hubo elecciones de presidente y de alcaldes, disminuyen dicha dependencia. Por otra parte, el autofinanciamiento de la inversión no fue representativo en ninguno de los tres modelos.

Por lo tanto, se encuentra que un cambio marginal unitario en la variación marginal de las transferencias impacta la dependencia fiscal en apenas $0.006 \%$. A su vez, un incremento del $1 \%$ en ingresos tributarios sobre los ingresos totales disminuye la dependencia fiscal en $0.11 \%$. Este resultado es lógico, pues a medida que el municipio recauda una mayor cantidad de tributos, se espera una reducción de la relación de las transferencias sobre los ingresos totales, lo que genera un mayor nivel de financiamiento con recursos propios y, por tanto, un mayor nivel de autonomía administrativa.

Por otra parte, a medida que aumentan los gastos de funcionamiento sobre los ingresos totales, se espera una mayor 
presión por recursos. Este resultado se evidencia en el modelo estimado, ya que si la relación anterior se incrementa en $1 \%$, la dependencia fiscal se ve afectada positivamente en $0.19 \%$. También es de esperar que la mayor cantidad de población traiga consigo una mayor dependencia fiscal, por la necesidad de cubrir la mayor demanda de servicios del Estado, para los cuales los municipios deben recurrir a mayores recursos transferidos desde el gobierno central. Así, cuando en promedio se incrementa la población en $1 \%$ en los municipios de sexta categoría en el país, la dependencia fiscal de estos municipios aumenta en un aproximado de $0.05 \%$.

Para no desconocer la fuerte influencia que tiene la actividad política en la distribución y aprobación de los presupuestos tanto en el nivel central como territorial, en la estimación se incluyeron dos variables de tipo político, con las cuales se intentó capturar la incidencia que generan los años electorales, cuando se eligen presidente y alcalde, sobre la dependencia fiscal, como forma de verificar que esta responde a un ciclo político (Delgado \& Acero, 2015). En el caso concreto se encuentra que para los años en los que se llevan a cabo elecciones de presidente y de alcaldes, la dependencia fiscal disminuye en $0.05 \mathrm{y}$ $0.08 \%$ respectivamente. Podría también sugerirse que, por una parte, para los años de elecciones populares en el país, muchos gastos públicos están condicionados a la ley de garantías que restringe la contratación y, en consecuencia, son años de una restricción de gastos en las entidades públicas que en el tiempo pueden disminuir la dependencia fiscal de los municipios; $y$, por otra parte, los procesos electorales hacen que las dinámicas políticas dirijan recursos hacia los municipios, vía recursos de inversión, para financiar o cofinanciar proyectos de iniciativa local, que responden a una lógica de mantenimiento de la dirigencia política territorial engranada con la dirigencia nacional, tanto en el Ejecutivo como en el Legislativo, que se activa cada vez que se requiere la movilización del electorado para elegir mandatarios en ambas instancia de gobierno.

Por último, un aumento del $1 \%$ en las necesidades básicas insatisfechas trae consigo un incremento del $0.09 \%$ en la dependencia fiscal. Este resultado también resulta lógico, pues, ante un deterioro de las condiciones de vida de los habitantes del municipio, existe una mayor demanda de los servicios del Estado, especialmente en términos de salud, educación, vivienda y saneamiento básico, que requieren de mayor gasto público y mayores recursos transferidos.

Una forma de evidenciar el comportamiento de la dependencia fiscal en el país para el periodo considerado 20002016, se puede observar a través del siguiente análisis gráfico (Figura 12), en donde se presentan algunos mapas que representan la evolución de la dependencia fiscal. 

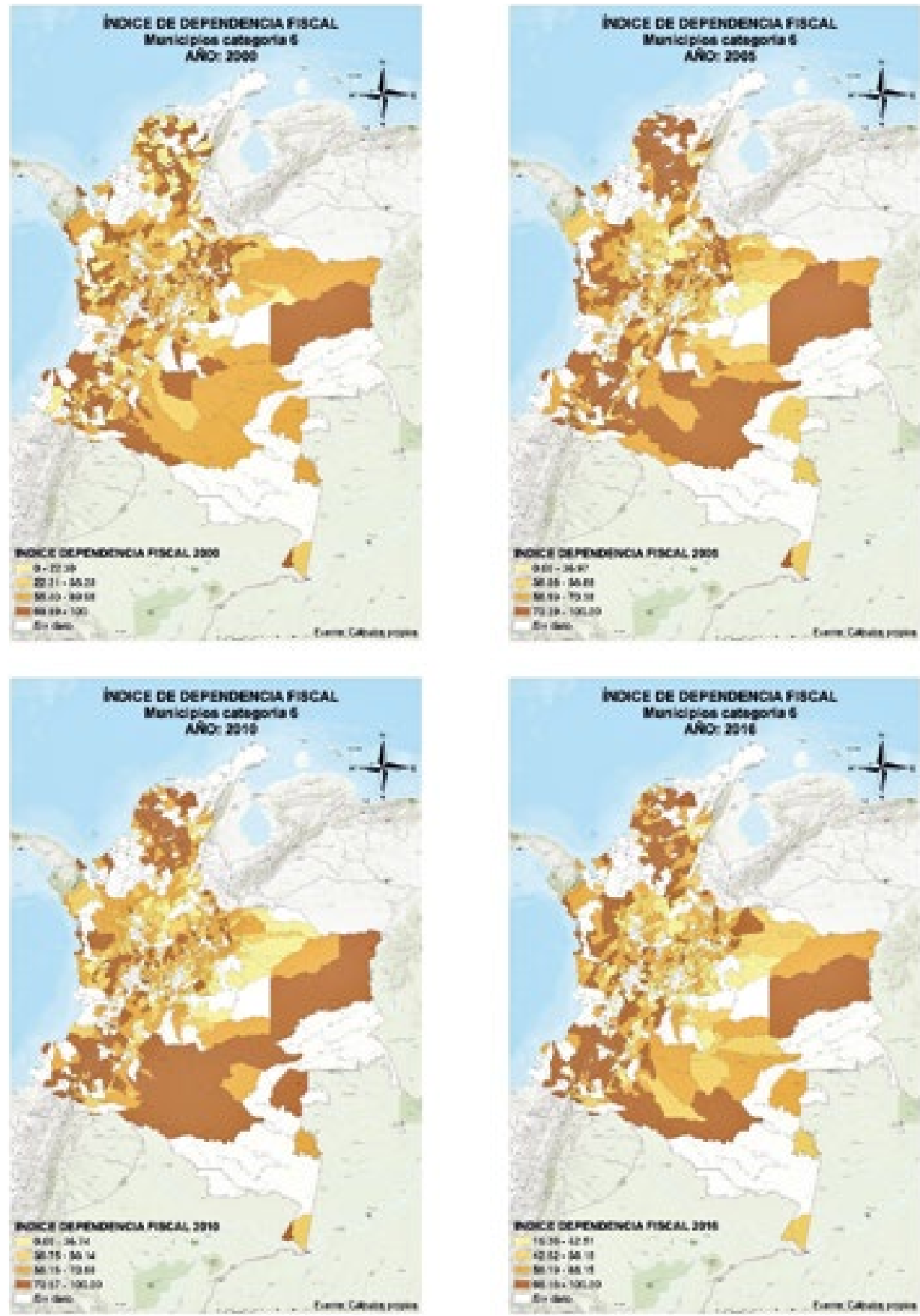

Figura 12. Mapas de dependencia fiscal en Colombia 2000-2016 
En la Figura 12 se puede observar cómo la dependencia fiscal de los municipios de sexta categoría se ha venido incrementando. Se muestra cómo, especialmente en municipios de la región Caribe, dicha dependencia es cada vez más marcada, así como también en municipios de la región Pacífica y de la Orinoquía. Al 2016, los municipios son más dependientes de las transferencias del gobierno central y muestran una tendencia que en el tiempo parecería acentuarse, lo que implica, desde lo financiero, que cada vez los municipios tienen menor capacidad de generar recursos propios, por lo que su sostenibilidad fiscal depende del sistema de reparto que establezca el Congreso Nacional; y, desde lo social, señala la incapacidad de los gobiernos locales para responder a unas necesidades crecientes que demandan mayores inversiones, cuya autonomía para atenderla está limitada a los lineamientos que fije el SGP.

Así las cosas, mientras los municipios de sexta categoría de Colombia sigan soportando sus recaudos principalmente sobre un catastro desactualizado, unas actividades económicas poco desarrolladas y el consumo de combustibles fósiles, continuará en entredicho su sostenibilidad financiera y su capacidad de gestionar de manera autónoma el desarrollo económico y social local.

\section{CONCLUSIONES}

En la evolución del proceso de descentralización política, administrativa y fiscal en Colombia se ha venido asignan- do a los entes territoriales una serie de competencias y responsabilidades que antes asumía el gobierno central, más aquellas que han surgido por el devenir histórico del país. Y para asumir estos compromisos, el marco legal vigente dispuso el traslado de una serie de recursos provenientes de los ingresos públicos del nivel central al local, bajo el denominado régimen de transferencias; sin embargo, este esquema de transferencias convirtió la mayor parte de los municipios en dependientes del gobierno nacional, habida cuenta de que la mayoría de ellos (87.9\%), de acuerdo con su capacidad de generación de rentas propias, se encuentran clasificados como de sexta categoría (según la Ley 617 del 2000), por su bajo nivel de tributación, que reside particularmente en los impuestos predial, industria y comercio, y la sobretasa a los combustibles, gravámenes de escaso recaudo debido al atraso en la actualización catastral, la estrechez económica local y la baja comercialización de combustibles que existe en esas jurisdicciones.

En esa medida, las transferencias, primero reguladas por el situado fiscal y luego por el Sistema General de Participaciones (SGP), se convirtieron en la principal y mayoritaria fuente de financiación de los municipios colombianos de sexta categoría, ya que mientras los ingresos tributarios solo representan, en promedio un $12.07 \%$ de los ingresos totales de estas localidades, a lo largo del periodo de análisis las transferencias constituyeron, en promedio, el $58.02 \%$ 
de los ingresos totales durante estos mismos años. Razón por la cual las inversiones de carácter social o de infraestructura física que requirieron las comunidades como mecanismo para mejorar sus condiciones de vida, se financiaron primordialmente gracias a los dineros recibidos por los municipios por concepto de transferencias (88.51 \%), debido a que la capacidad de autofinanciamiento de la inversión, en promedio, solo llegó al $11.49 \%$.

Este panorama se corrobora gracias a la estimación econométrica efectuada, según la cual la dependencia fiscal de los municipios de sexta categoría en Colombia es impactada positivamente por variables como la participación de los gastos de funcionamientos en los ingresos totales, el índice de NBI municipal y el crecimiento poblacional, en tanto que dicha dependencia fiscal puede reducirse gracias a la incidencia que tienen sobre ella variables como la participación de los ingresos tributarios en los ingresos totales municipales (capacidad de generación de rentas propias) y los eventos de tipo político-electoral mediante los cuales se elige presidente y alcalde, pues en estos años electorales el flujo de recursos que se orientan hacia los territorios para financiar inversiones específicas, diferentes a las establecidas en el régimen de transferencias, se aumentan considerablemente, como reflejo de la articulación entre la clase política local y la nacional, que comparten intereses electorales particulares.

Así mismo, las estimaciones indican que la dependencia fiscal en los municipios de referencia tiene un carácter estructural, que no logra ser explicado por las variables introducidas, sino que puede depender más del esquema de descentralización implementado en Colombia, la estrechez de las fuentes de tributación municipal, la baja gestión tributaria local y el bajo nivel de cultura política en las regiones que hace reproducir modelos electorales clientelistas, entre otras circunstancias que, en conjunto, fortalecen el centralismo fiscal, las castas políticas locales (reflejo de las nacionales) y el atraso de muchas zonas del país (región Pacífica, algunas áreas de la región Caribe y la mayor parte de la Orinoquía y la Amazonía). Situación que contradice toda la retórica que justificó la implementación de la descentralización en el país, pues, en la práctica, ha logrado un gobierno central más fuerte y unos gobiernos territoriales más dependientes, en particular aquellos que representan los municipios más pobres, presupuestalmente hablando, como es el caso de los catalogados en la sexta categoría. 


\section{REFERENCIAS}

Aghón, G. E. (1993). Descentralización fiscal: marco conceptual. Serie política fiscal 44. Comisión Económica para América Latina y el Caribe CEPAL. Recuperado de: https://repositorio.cepal.org/bitstream/handle/11362/9485/1/ S9300147_es.pdf

Bardhan, P. (2002). Decentralization, the Government and Development. The Journal of Economic Perspectives, 16(4), 185-205 https://doi. org $/ 10.1257 / 089533002320951037$

Bonet, J., Pérez, G. J. \& Ricciulli, D. (2017). ¿Hay pereza fiscal territorial en Colombia? Banco de la República de Colombia, Documento de Trabajo sobre Economía Regional y Urbana, (261). Recuperado de: http://www.banrep.gov. co/es/publicaciones/documento-de-trabajo-economia-regional-y-urbana-261

Bonet, J., Pérez, G. J. \& Montero, L. (2018). Las finanzas públicas territoriales en Colombia: dos décadas de cambios. Documento de Trabajo sobre Economía Regional y Urbana, (267).

Center for Economic and Social Rights -CESR- (2017). Política fiscal para la igualdad y los derechos. Recuperado de: http:/www.cesr.org/sites/default/files/ Politica_Fiscal_Igualdad_Derechos.pdf

CEPAL. (2001). Desarrollo económico local y descentralización en América Latina: análisis comparativo. Recuperado de: http://200.9.3.98/handle/11362/2691

Congreso de la República de Colombia. (2000). Ley 617 de 2000. Bogotá: Imprenta Nacional.

Congreso de la República de Colombia. (2001). Ley 715 de 2001. Sistema General de Participaciones. Bogotá: Imprenta Nacional.

Departamento Nacional de Planeación -DNP-. (2008). Técnicas para el análisis de la gestión financiera de las entidades territoriales. Bogotá: Imprenta Nacional.

Departamento Nacional de Planeación -DNP-. (2011). Desempeño fiscal de los departamentos y municipios: 2011. Bogotá: Imprenta Nacional. 
Departamento Nacional de Planeación -DNP-. (2018). Guía de distribución del Sistema General de Regalías entre fondos y beneficiarios. Bogotá: Imprenta Nacional.

Delgado, S. \& Acero, L. (2015). Análisis de la dependencia fiscal de los municipios de sexta categoría del departamento de Boyacá, durante el periodo 1996-2012. Apuntes del Cenes, 34(60), 215-246. doi: https://doi.org/10.19053/22565779.3780

Finot, I (2006). Descentralización y viabilidad del desarrollo local en América Latina. Revista del CLAD Reforma y Democracia, (34).

Fondo Monetario Internacional -FMI- (2002). Programación financiera. Métodos y aplicación al caso de Colombia. Capitulo 3. Recuperado de: http://www.imf. org/external/pubs/ft/finpro/esl/pdf/chapter3.pdf

Giraldo, C. (2009). Finanzas públicas en América Latina. La economía política. Bogotá: ESAP, Ediciones Desde Abajo.

Herrera, A. (2003). Régimen presupuestal de los municipios en Colombia. Revista del Derecho, (19).

Lozano, I. \& Julio, J. (2016, ago.). Descentralización fiscal y crecimiento económico en Colombia: evidencia de datos de panel a nivel regional. Revista Cepal, (119). https://doi.org/10.18356/d873c672-es

Martínez, L. (2017). Sources of Revenue and Government Performance: Evidence from Colombia. Working Paper. USA: University of Chicago. https://doi. org/10.2139/ssrn.3273001

Ministerio de Hacienda y Crédito Público de Colombia. (1996). Decreto 111 de 1996. Estatuto Orgánico del Presupuesto. Bogotá: Imprenta Nacional.

Montecinos, E. (2005). Los estudios de descentralización en América Latina: una revisión sobre el estado actual de la temática. Revista Eure, 31(93), 73-88. https://doi.org/10.4067/S0250-71612005009300005

Oates, W. (1999). An Essay on Fiscal Federalism. Journal of Economic Literature, 37(3). https://doi.org/10.1257/jel.37.3.1120

Ramírez, J.M. \& Bedoya, J.G. (2014). Regalías directas por hidrocarburos y esfuerzo fiscal municipal en Colombia. Coyuntura Económica, 44(2), 15-34. 
Ramírez Zambrano, J., Zambrano Miranda, M., Mogrovejo, J., \& Carreño Montaño, J. (2016). Informalidad laboral en los departamentos de Norte de Santander, Nariño, La Guajira y Cesar. Apuntes Del Cenes, 35(62), 125-145. https://doi. org/10.19053/22565779.5232

Restrepo, J. C. (2015). Hacienda pública. (10. ${ }^{a}$ ed.). Bogotá: Universidad Externado de Colombia.

Roth, A. (2017). Politicas públicas: formulación, implementación y evaluación. Bogotá: Aurora.

Valencia Cárdenas, M., Trochez González, J., Vanegas López, J., \& Restrepo Morales, J. (2016). Modelo para el análisis de la quiebra financiera en pymes agroindustriales antioqueñas. Apuntes Del Cenes, 35(62), 147-168. https://doi. org/10.19053/22565779.4310 